\title{
Study on Synthesis and Antibacterial Properties of Ag NPs/GO Nanocomposites
}

\author{
Lei Huang, Hongtao Yang, Yanhua Zhang, and Wei Xiao \\ Research Institute for New Materials Technology, Chongqing Key Laboratory of Environmental Materials \& Remediation Technologies, \\ Chongqing University of Arts and Science, Chongqing 402160, China
}

Correspondence should be addressed to Yanhua Zhang; zyhcoco@163.com and Wei Xiao; showame@aliyun.com

Received 25 January 2016; Revised 3 April 2016; Accepted 14 April 2016

Academic Editor: Xuping Sun

Copyright (C) 2016 Lei Huang et al. This is an open access article distributed under the Creative Commons Attribution License, which permits unrestricted use, distribution, and reproduction in any medium, provided the original work is properly cited.

Using graphene oxide as substrate and stabilizer for the silver nanoparticles, silver nanoparticles-graphene oxide (Ag NPs/GO) composites with different Ag loading were synthesized through a facile solution-phase method. During the synthesis process, $\mathrm{AgNO}_{3}$ on $\mathrm{GO}$ matrix was directly reduced by $\mathrm{NaBH}_{4}$. The structure characterization was studied through X-ray diffraction (XRD), atomic force microscopy (AFM), high-resolution transmission electron microscope (HRTEM), ultraviolet-visible spectroscopy (UV-Vis), and selected area electron diffraction (SAED). The results show that Ag nanoparticles (Ag NPs) with the sizes ranging from 5 to $20 \mathrm{~nm}$ are highly dispersed on the surfaces of GO sheets. The shape and size of the Ag NPs are decided by the volume of initial $\mathrm{AgNO}_{3}$ solution added in the GO. The antibacterial activities of Ag NPs/GO nanocomposites were investigated and the result shows that all the produced composites exhibit good antibacterial activities against Gram-negative (G-) bacterial strain Escherichia coli (E. coli) and Gram-positive (G+) strain Staphylococcus aureus (S. aureus). Moreover, the antibacterial activities of Ag NPs/GO nanocomposites gradually increased with the increasing of volume of initial $\mathrm{AgNO}_{3}$ solution added in the GO and this improvement of the antibacterial activities results from the combined action of size effect and concentration effect of Ag NPs in Ag NPs/GO nanocomposites.

\section{Introduction}

Graphene, a well-defined two-dimensional honeycomb structure of carbon atoms with $\mathrm{sp}^{2}$ bond [1], has attracted a great deal of attention due to its outstanding electronic, thermal, and mechanical properties, which lead to their promising applications in nanoelectronics, conductive thin films, supercapacitors, biosensors, and nanomedicine fields [2-7]. Graphene oxide (GO), the oxide of graphene, has a huge surface area and strongly hydrophilic ability due to the large number of oxygen bonds in its edges and defective sites, such as carboxylic $(-\mathrm{COOH})$, hydroxyl $(\mathrm{C}-\mathrm{OH})$, carbonyl $(\mathrm{C}=\mathrm{O})$, and epoxide groups $(\mathrm{C}-\mathrm{O}-\mathrm{C})[8,9]$. Its hydrophilic ability contributes to forming stable colloidal dispersions in water [10]. Moreover, those functional groups have been confirmed to own reducibility [11] and have been actively used to build new composites [12-15].

Silver $(\mathrm{Ag})$ has been known as an antibacterial agent for centuries. It has been reported that Ag NPs and hybrid
Ag nanocomposites are effective biocides against numerous kinds of bacteria, fungi, and viruses by releasing $\mathrm{Ag}^{+}$that can inactivate the microorganism cells by destroying the cell membrane and replication ability of DNA [16, 17]. Due to their promising antibacterial capability, Ag NPs are often used as pharmaceutical gents, antiseptic, and disinfectant [18-20]. Meanwhile, many studies have shown that monodispersed Ag NPs with small size are desirable for the antibacterial control system, because of the powerful cell penetration and high specific surface area [21, 22]. However, there are two big challenges for Ag NPs in applications: nanoparticles aggregation and nanomaterial recovery, which would lead to losing the antibacterial activity of Ag NPs [23]. It is a good measure to load Ag NPs on GO or reduced graphene oxide (RGO) matrix, which has huge specific surface area that can prevent $\mathrm{Ag}$ NPs aggregation, to form $\mathrm{Ag}$ NPs/GO or Ag NPs/RGO nanocomposites with stable and effective antibacterial activities. 


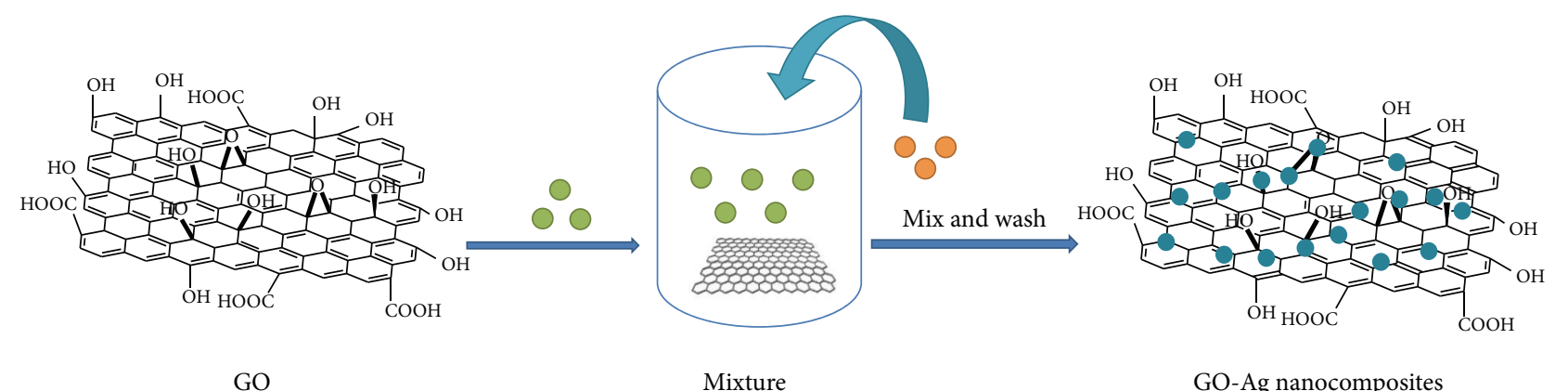

$\mathrm{AgNO}_{3}$
$\mathrm{NaBH}_{4}$
$\mathrm{Ag}$ nanoparticle

FIGURE 1: Schematic illustration of the preparation of GO-Ag nanocomposites.

The synthesis of Ag NPs/GO or Ag NPs/RGO composites has been reported by several researchers [24-32]. Zainy et al. reported a straightforward and scalable method for the preparation of high purity reduced graphene oxide/silver (RGO/Ag) nanocomposites via a rapid thermal reduction method [24]. Liu et al. reported that graphene oxide-Ag nanoparticle composites were synthesized through a twophase (toluene-water) process [25]. Sun and his group prepared Ag nanoparticles/reduced graphene oxide nanocomposites by direct adsorption of preformed negatively-charged Ag NPs $[26,27]$ or in situ chemical reduction of silver salts on reduced graphene oxide sheets $[26,28]$. These composites all exhibited excellent activity for enzymeless hydrogen peroxide detection. However, these approaches have experienced difficulty in comparing and researching the different size and loading of Ag NPs on GO or RGO sheets. Herein, we report a facile solution-phase synthesis method for $\mathrm{Ag}$ NPs/GO nanocomposites by direct reduction of $\mathrm{AgNO}_{3}$ on GO matrix with $\mathrm{NaBH}_{4}$ as a reducing agent. It is worth highly lighting that the reaction process did not require a vacuum or inert atmosphere and can be further researched with in situ characterization. With the aim of evaluating the antibacterial efficiency of Ag NPs/GO with different Ag loading, we studied that the antimicrobial activity of $\mathrm{Ag}$ NPs/GO nanocomposites against the Gram-negative bacteria Escherichia coli (E. coli) and the Gram-positive bacterium Staphylococcus aureus (S. aureus).

\section{Materials and Methods}

2.1. Materials. All chemicals used were of analytical reagent grade and used without further purification. Graphite powder (<20 micron) and $\mathrm{AgNO}_{3}$ (99.8\%) were obtained from J\&K Chemical Co. $\mathrm{NaBH}_{4}(>99 \%), \mathrm{H}_{2} \mathrm{O}_{2}\left(30 \%\right.$ (w/v)), $\mathrm{KMnO}_{4}$, and hydrochloric acid were purchased from Chengdu Kelong Chemical Reagent Co., Ltd. Luria-Bertani (LB) nutrient solution $(\mathrm{g} / \mathrm{L}$, tryptone $10 \mathrm{~g}$; yeast extract $5 \mathrm{~g}, \mathrm{NaCl} 5 \mathrm{~g})$ was used as-received and without any further purification. The strains employed in this work were the Gram-negative bacterium E. coli (ATCC 25922) and the Gram-positive bacterium $S$. aureus (ATCC 25923).
2.2. Preparation of Graphene Oxide Nanosheets Suspension. Briefly, the water soluble GO were prepared by oxidizing pristine graphite according to the modified hummers method [33] and our previous reports [34]. The detailed procedure is as follows: $2 \mathrm{~g}$ graphite powder was added into $150 \mathrm{~mL}$ concentrated $\mathrm{H}_{2} \mathrm{SO}_{4}$ under stirring in an ice bath. Then $25 \mathrm{~g} \mathrm{KMnO}_{4}$ was slowly added at the temperature of $5^{\circ} \mathrm{C}$ for $30 \mathrm{~min}$ with stirring followed by increasing to $35^{\circ} \mathrm{C}$ for $2 \mathrm{~h}$. After that, $250 \mathrm{~mL}$ deionized water was added slowly into this mixture at the temperature below $50^{\circ} \mathrm{C}$. After 20 minutes, $1000 \mathrm{~mL}$ deionized water was then injected into the mixture followed by adding $30 \mathrm{~mL}$ of $30 \% \mathrm{H}_{2} \mathrm{O}_{2}$ drop by drop. The mixture was filtered and washed with $5 \% \mathrm{HCl}$ aqueous solution and deionized water to remove metal ions and the acid. The resulting solid was dried in air and redispersed in water to make graphite oxide dispersion $(0.1 \mathrm{mg} / \mathrm{mL})$. Finally, the homogeneous reddish brown GO nanosheets solution $(0.1 \mathrm{mg} / \mathrm{mL})$ was obtained by ultrasonic exfoliation of prepared graphite oxide dispersion for $3 \mathrm{~h}$.

2.3. Preparation of $\mathrm{Ag} \mathrm{NPs/GO} \mathrm{Nanocomposites.} \mathrm{Ag} \mathrm{NPs} \mathrm{were}$ synthesized by in situ reducing $\mathrm{AgNO}_{3}$ solution on the surfaces of GO with $\mathrm{NaBH}_{4}$ as reductant (Figure 1). The different volume $(2 \mathrm{~mL}, 4 \mathrm{~mL}, 6 \mathrm{~mL}$, and $8 \mathrm{~mL})$ of the $\mathrm{AgNO}_{3}$ aqueous solution $(0.025 \mathrm{~mol} / \mathrm{L})$ was gradually added to $25 \mathrm{~mL}$ $\mathrm{GO}$ aqueous solution of $(0.1 \mathrm{mg} / \mathrm{mL})$. The reaction mixture was stirred for $30 \mathrm{~min}$ at room temperature followed by the gradual addition of $10 \mathrm{~mL} \mathrm{NaBH} 4(2.0 \mathrm{~g} / \mathrm{L})$ under vigorous stirring. The color of the mixture turns from reddish brown into dark brown to grey depending on the volume of $\mathrm{AgNO}_{3}$ aqueous solution and the resultant mixture was maintained stirring for $6 \mathrm{~h}$. Then the Ag NPs/GO nanocomposites were obtained by centrifugation, washed with deionized water, and then dried in vacuum drying oven overnight. These composites were named $\mathrm{GO}-\mathrm{Ag} X(X=2,4,6,8)$ according to the volume of $\mathrm{AgNO}_{3}$ aqueous solution added into $\mathrm{GO}$ solution. For example, GO-Ag2 is the Ag NPs/GO nanocomposite with $2 \mathrm{~mL}$ of $\mathrm{AgNO}_{3}$ aqueous solution added into GO solution.

2.4. Antibacterial Activity. In order to explore the antibacterial activities of synthesized Ag NPs/GO nanocomposites, 

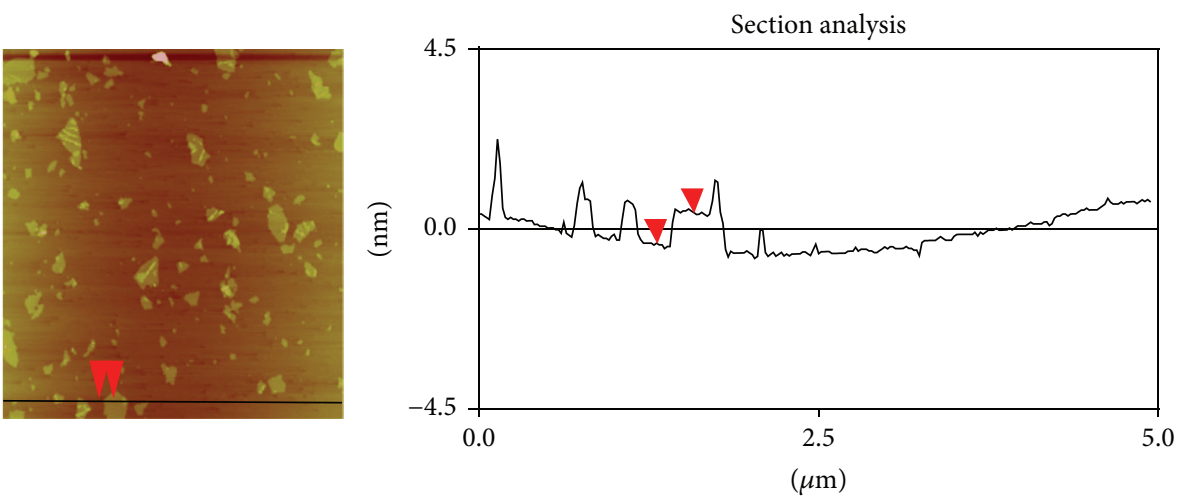

(a)

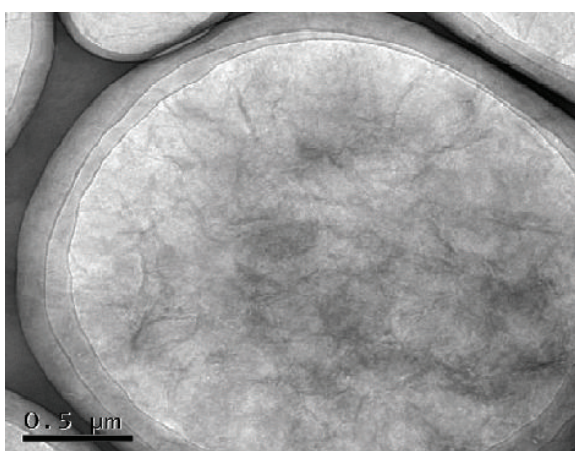

(b)

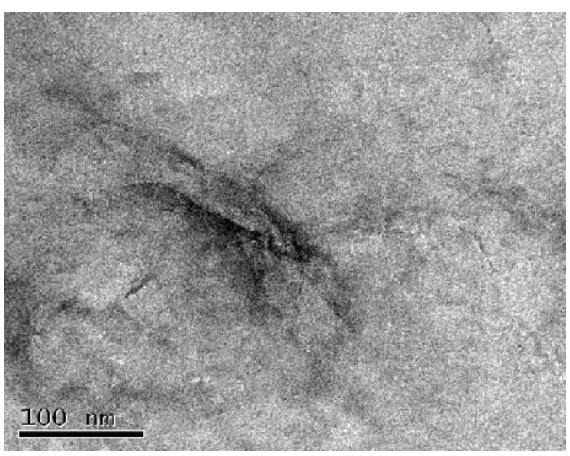

(c)

FIgURE 2: AFM images of GO (a); TEM images of GO with low (b) and high (c) magnifications.

the Gram-negative bacterium E. coli (ATCC 25922) and the Gram-positive bacterium S. aureus (ATCC 25923) were introduced in our experiments. The bacterial strains grew in $\mathrm{LB}$ nutrient solution at $37^{\circ} \mathrm{C}$ with continuous shaking at $200 \mathrm{rpm}$. The optical densities (OD; it was measured in a microtiter plate (ELISA) reader in $600 \mathrm{~nm}$ wavelength) of the bacterium solution were 0.5 . According to the agar well diffusion assay [35], $10 \mu \mathrm{L}$ of bacterial cultures (approximately $10^{8}$ colony forming units [CFUs]) was inoculated on nutrient agar medium. Then, $10 \mu \mathrm{L}$ of $\mathrm{Ag}$ NPs/GO aqueous dispersions with different volume of $\mathrm{AgNO}_{3}$ aqueous solution was, respectively, placed on filter papers with a diameter of $6.35 \mathrm{~mm}$ and then placed the filter paper onto the seeded agar plate. After $24 \mathrm{~h}$ incubation at $37^{\circ} \mathrm{C}$, the diameters of the inhibition zones were measured and optical images were documented by an ordinary camera.

2.5. Bacterial Growth Kinetics. The bacterial growth kinetics was studied by colorimetric method [36]. $50 \mu \mathrm{L}$ of bacterial suspension was inoculated individually in $5 \mathrm{~mL}$ of LB nutrient solution supplemented with $50 \mu \mathrm{L}$ Ag NPs/GO nanocomposites aqueous dispersions and then incubated at $37^{\circ} \mathrm{C}$ temperature with continuous agitation at $200 \mathrm{rpm}$. Growth kinetics was determined by measuring OD in an ELISA microtiter plate reader at $600 \mathrm{~nm}$ at every $1 \mathrm{~h}$ interval from the time of inoculation. The test was repeated three times.
2.6. Characterization. Transmission electron microscopy (TEM) observation was conducted with a FEI Tecnai G2 F20 instrument. The high-resolution transmission electron microscopy (HRTEM) images were taken by a TECNAI-T 30 model instrument operated at an accelerating voltage of $300 \mathrm{kV}$. X-ray diffraction (XRD) analysis was recorded on a XRD-6000 X-ray diffractometer (Shimadzu) with $\mathrm{Cu} \mathrm{K} \alpha$ radiation $(\lambda=1.5406 \AA)$. Atomic Force Microscope (AFM) images were performed on a Veeco MultiMode/NanoScope IIIa Multimode instrument. UV-Vis absorption spectra were collected on a Hitachi U-4100 spectrophotometer. The optical densities (OD) were measured by Thermo Multiskan MK3 in $600 \mathrm{~nm}$ wavelength.

\section{Results and Discussion}

3.1. Characterization of the GO Nanosheets and Ag NPs/GO Nanocomposites. In this work, GO was selected as the substrate and stabilizer to prepare Ag NPs/GO nanocomposites. AFM was employed to establish the thickness and surface roughness of prepared GO. The cross-sectional view of the typical AFM image (Figure 2(a)) indicates that the GO has a uniform thickness of about $1.3 \mathrm{~nm}$. To further characterize the exact structures of GO, we conducted TEM examination. TEM images of GO (Figures 2(b) and 2(c)) show that large sheets were observed to be situated on the top of the grid, 


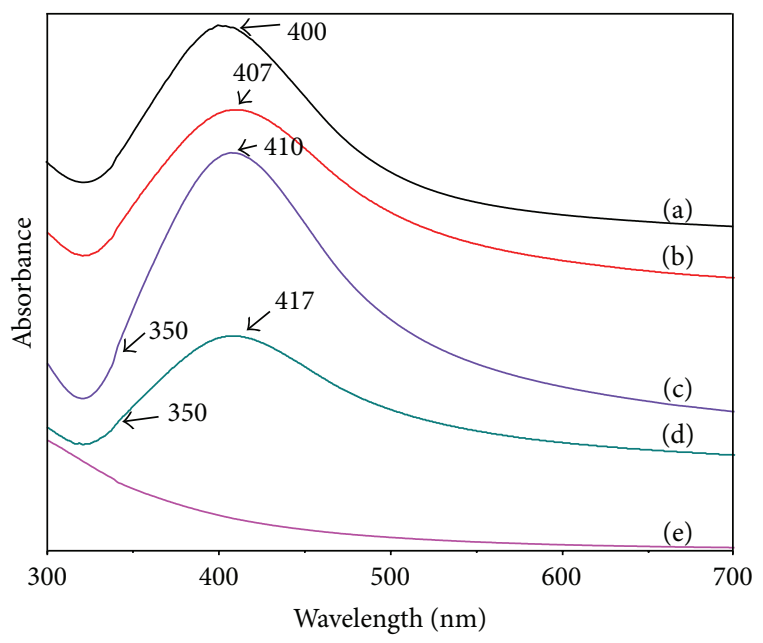

FIGURE 3: UV-Vis spectra of the Ag NPs/GO suspension in aqueous medium with different $\mathrm{Ag}$ loading $(\mathrm{a}-\mathrm{d})$ and $\mathrm{GO}$ suspension without $\mathrm{AgNO}_{3}$ (e). GO-Ag2 (a), GO-Ag4 (b), GO-Ag6 (c), GO-Ag8 (d), and $\mathrm{GO}$ suspension without $\mathrm{AgNO}_{3}(\mathrm{e})$.

where they resembled silk veil waves, illustrating the flakelike shapes of graphene.

The UV-Vis spectroscopy was used to study the formation of the Ag NPs in GO dispersed suspension. Figure 3 showed the UV-Vis spectra of the Ag NPs/GO nanocomposites with different volume of aqueous $\mathrm{AgNO}_{3}$ solution. The appearance of characteristic surface plasmon bands at $400 \mathrm{~nm}$ indicates the formation of Ag NPs on GO water suspension in all the samples [31]. As shown in this figure, when $2 \mathrm{~mL}$ of $\mathrm{AgNO}_{3}$ aqueous solution $(0.025 \mathrm{~mol} / \mathrm{L})$ was used, the surface plasmon band of the Ag NPs is appeared at $400 \mathrm{~nm}$. However, when higher volume of $\mathrm{AgNO}_{3}$ aqueous solution added, the absorption band was shifted gradually to longer wavelength, such as $407 \mathrm{~nm}$ for $4 \mathrm{~mL}, 410 \mathrm{~nm}$ for $6 \mathrm{~mL}$, and $417 \mathrm{~nm}$ for $8 \mathrm{~mL}$. Obviously, the shifting of the absorption peak towards longer wavelength indicates that Ag NPs with larger size have formed [37]. Further research by TEM analysis can also verify this conclusion. Meanwhile, a hump at $350 \mathrm{~nm}$ in case of synthesized Ag NPs using $6 \mathrm{~mL}$ and $8 \mathrm{~mL}$ of $\mathrm{AgNO}_{3}$ implies polydispersity of the size and shape of the nanoparticles. The reason for surface plasmon band shifts is that the particle size, shape, chemical surrounding, adsorbed species on the surface, and dielectric constant have changed [38-41].

The XRD analysis is further used to confirm the formation of the Ag NPs/GO nanocomposites. As shown in Figure 4 , the XRD peaks at $38.2^{\circ}, 44.1^{\circ}, 64.7^{\circ}$, and $77.2^{\circ}$ are assigned to (111), (200), (220), and (311) crystallographic planes of face-centered cubic (fcc) Ag (JCPDS number 070783), respectively. In comparison with Ag NPs, there are no change in the curve of $\mathrm{Ag} \mathrm{NPs/GO}$ nanocomposites and no obvious diffraction peaks of GO which were observed in the $\mathrm{Ag}$ NPs/GO nanocomposites, because the regular stack of GO was destroyed by the intercalation of Ag NPs in GO-metal nanocomposites [31, 42, 43]. It can be seen from Figure 4 that when the volume of $\mathrm{AgNO}_{3}$ aqueous solution increased, the intensities of XRD peaks of all samples are gradually added

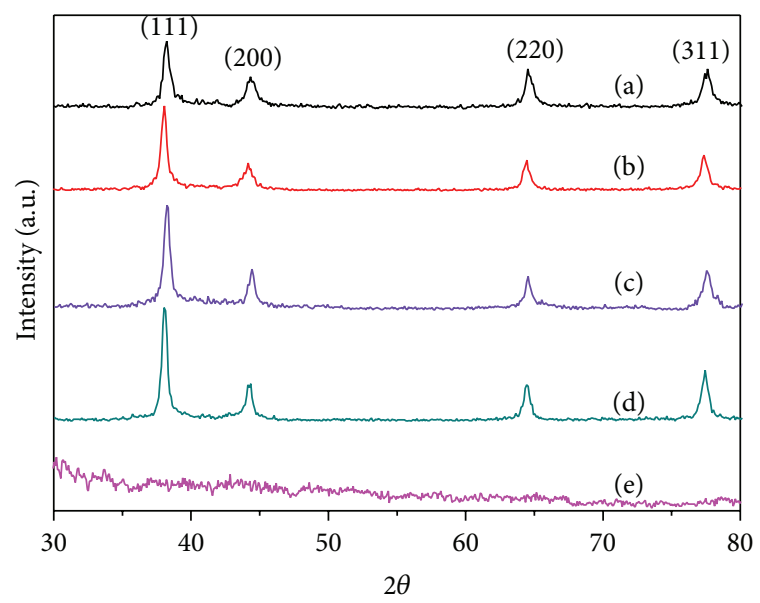

FIgURE 4: XRD of the Ag NPs/GO composites with different Ag loading (a-d) and GO without Ag nanoparticles (e). GO-Ag2 (a), GO-Ag4 (b), GO-Ag6 (c), GO-Ag8 (d), and GO (e).

to get close to those of diffraction peaks of crystalline $\mathrm{Ag}$ and the full width at half maxima become narrow and sharp, which confirms that the nanoparticles are composed of pure crystalline Ag in Ag NPs/GO nanocomposites.

The mean particle size of Ag nanoparticles in the nanocomposite can be calculated from the broadening of the (111) XRD peak of Ag according to Scherrer's equation as follows:

$$
D=\frac{0.89 \lambda}{B \cos \theta}
$$

where $D$ is the average grain size. $\lambda$ is the $\mathrm{X}$-ray wavelength $(0.15405 \mathrm{~nm}$ in this study). $B$ is full width at half maximum (FWHM) of (111) diffraction peak. $\theta$ is the diffraction angle for the (111) plane.

The calculated results from Scherrer formula indicate that the average particle sizes of $\mathrm{Ag}$ in $\mathrm{GO}-\mathrm{Ag} 2, \mathrm{GO}-\mathrm{Ag} 4$, GOAg6, and GO-Ag8 are 13.9, 15.4, 16.3, and $17.7 \mathrm{~nm}$, respectively. It means that the size of Ag particles on surface of $\mathrm{GO}$ gradually increased with increasing of the volume of $\mathrm{AgNO}_{3}$ solution added.

Figure 5 shows the TEM images of Ag NPs/GO nanocomposites, which demonstrate that the spherical Ag NPs are homogeneously assembled on the GO surface, and the wide size distribution of $\mathrm{Ag}$ NPs ranges from 5 to $20 \mathrm{~nm}$ (Figures 3(a)-3(d)). Besides, a few of elongated spherical particles are observed in GO-Ag6 and GO-Ag8 samples that could result from the aggregation of the two or more Ag particles. It also show that the shapes and sizes of the Ag NPs are influenced by the volume variation of $\mathrm{AgNO}_{3}$ solution. When the Ag NPs/GO nanocomposites were synthesized using $2 \mathrm{~mL} \mathrm{AgNO}_{3}$ solution, a large number of spherical Ag NPs are formed (Figure 5(a)). However, when higher volumes of $\mathrm{AgNO}_{3}$ solution were added, variable particle shapes were observed, such as sphere, ellipsoid, and rod (Figures 5(a), 5(b), and 5(c)). Meanwhile, the particle sizes are gradually increased with the volumes increasing of $\mathrm{AgNO}_{3}$ solution. This conclusion is consistent with UV-Vis spectra and XRD analysis. 


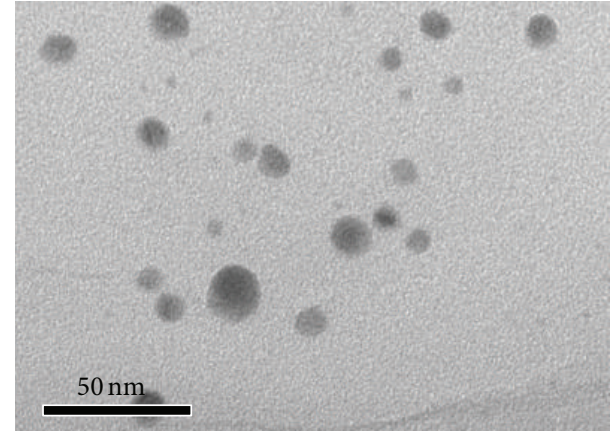

(a)

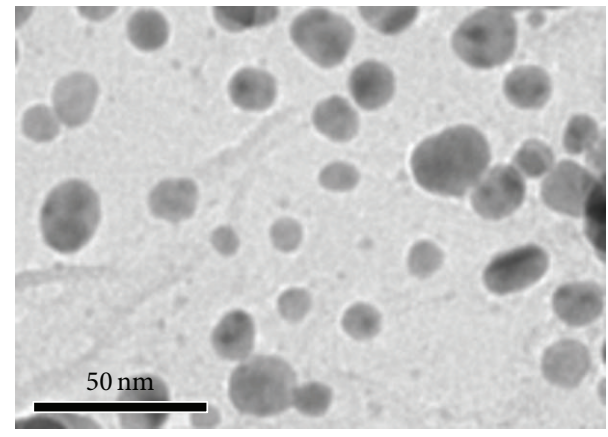

(c)

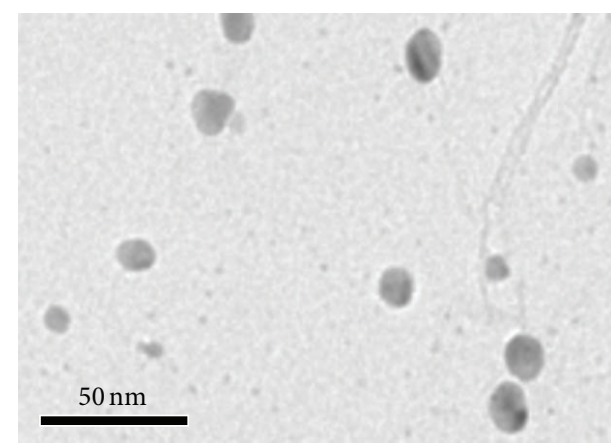

(b)

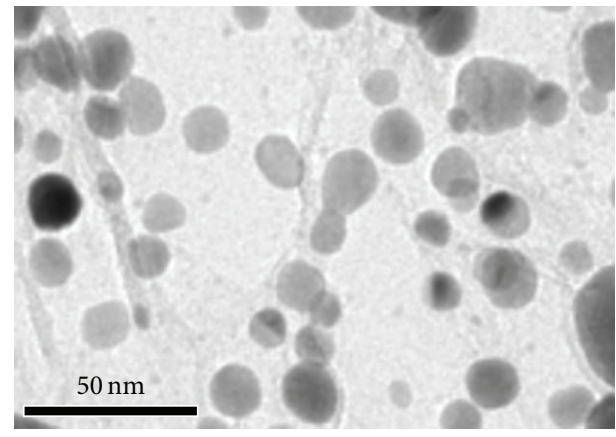

(d)

Figure 5: TEM images of Ag-GO nanocomposites. (a) GO-Ag2, (b) GO-Ag4, (c) GO-Ag6, and (d) GO-Ag8.

The HRTEM images of Ag NPs/GO nanocomposites show that Ag NPs are embedded on the GO sheets (Figure 6(a)). The measured lattice-fringe spacing of the nanoparticles is $0.236 \mathrm{~nm}$ (Figure 6(b)), which corresponds to the (111) crystal plane of Ag NPs. In addition, a typical selected area electron diffraction (SAED) pattern of GO-Ag2 sample was used to study the crystalline nature of the Ag NPs in the composite. The SAED image (Figure 6(c)) exhibits multiplecrystal diffraction features. The four visible diffraction rings are indexed as the crystal planes (111), (200), (220), and (311) of face-centered cubic (fcc) metallic silver, which clearly confirms the presence of Ag nanoparticles in the nanocomposites $[31,42]$. The results agree with that of the XRD analysis of pure Ag NPs (Figure 6(d)).

3.2. Antibacterial Tests. Gram-negative (G-) bacterial strain E. coli and Gram-positive (G+) strain S. aureus were chosen as the model organisms for evaluating antibacterial activity of the Ag NPs/GO nanocomposites. The bacterial growth kinetics of $\mathrm{Ag}$ NPs/GO nanocomposites with different $\mathrm{Ag}$ NPs loadings was monitored in $5 \mathrm{~mL} \mathrm{LB}$ broth. As shown in Figure 7, a growth delay was found against both E. coli (a) and $S$. aureus (b). The growth kinetics was studied based on the value of optical densities at $600 \mathrm{~nm}$ and the result reveals that the growth delay follows the order as $\mathrm{GO}<\mathrm{GO}-\mathrm{Ag} 2<\mathrm{GO}-$ Ag4 $<$ GO-Ag6 < GO-Ag8 (Figures 7(a) and 7(b)). Therefore, the loading of Ag NPs in the nanocomposites is a crucial parameter for antibacterial activity. With the volume of initial added $\mathrm{AgNO}_{3}$ solution increasing, the growth delay of $E$. coli and S. aureus increased, which indicates that the loading amount of Ag nanoparticles has prime effect on bacterial growth $[31,44]$.

The antibacterial activity of $\mathrm{Ag} \mathrm{NPs/GO}$ nanocomposites with adding different volume of $\mathrm{AgNO}_{3}$ solution was tested against two representative bacteria, E. coli and S. aureus, by measuring the diameter of inhibition zone (DIZ) in a disk diffusion test (Figure 8). The DIZ reflects the magnitude of susceptibility to microorganisms. The strains susceptible to disinfectants exhibit larger DIZ, whereas resistant strains exhibit smaller DIZ [45]. Compared with the negligible zone of inhibition around the GO disk, the disks supporting Ag $\mathrm{NPs} / \mathrm{GO}$ nanocomposites were surrounded by clear and significantly larger DIZs for both E. coli and S. aureus, indicating that both the bacterial strains were sensitive to all prepared Ag NPs/GO composites. As shown in Figure 8, the DIZ varies with the volume of added $\mathrm{AgNO}_{3}$ solution (the DIZ of $E$. coli: GO-Ag8 > GO-Ag6 > GO-Ag4 > GO-Ag2 > GO; the DIZ of S. aureus: GO-Ag8 > GO-Ag6 > GO-Ag4 > GOAg2 > GO), which indicates that the loading amount of Ag nanoparticles affects the antibacterial activity of Ag NPs/GO nanocomposites. Meanwhile, it also can be observed from Figures 8 and 9 that the DIZ in E. coli is obviously lager than that in S. aureus when the Ag NPs/GO composites possessed the same Ag loading, which means the nanocomposites are more effective against $E$. coli than $S$. aureus. The result is consistent with previous reports [46]. It may mainly be due to different cell wall structures of the two bacteria and different antibacterial mechanisms of Ag NPs/GO composites against them. For example, $G-$ bacteria possess a thin peptidoglycan layer (thickness: $7-8 \mathrm{~nm}$ ), whereas $\mathrm{G}+$ bacteria possess a 


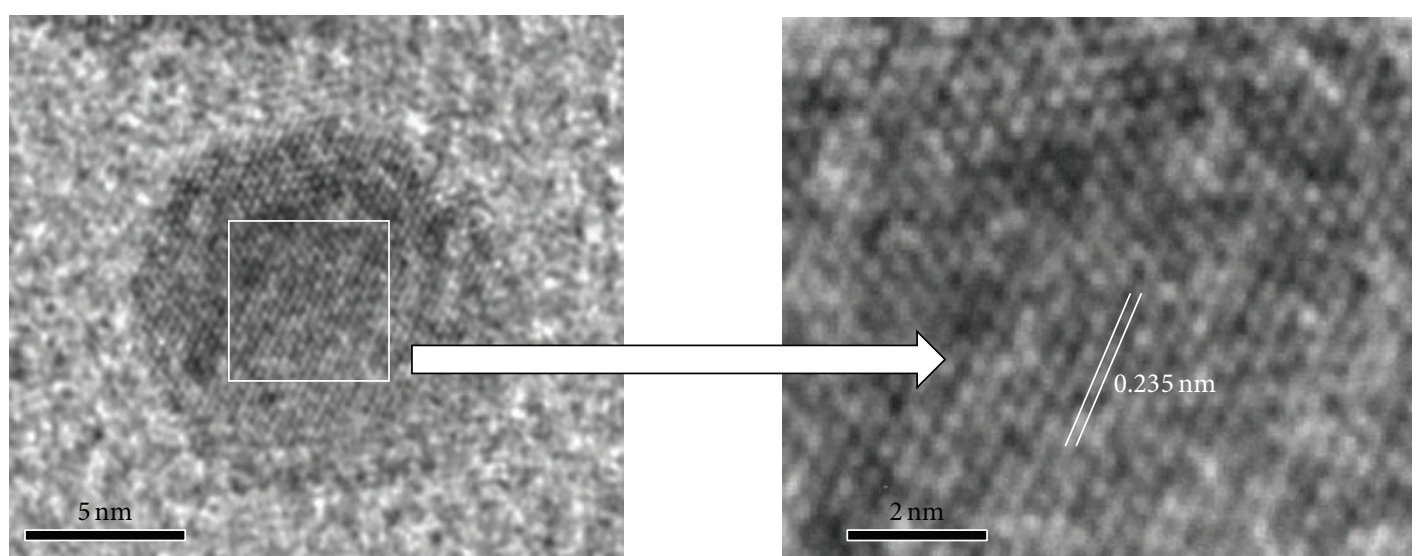

(a)

(b)

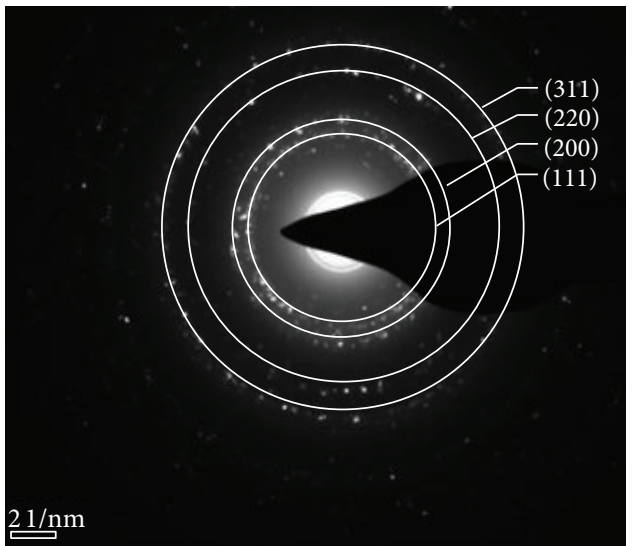

(c)

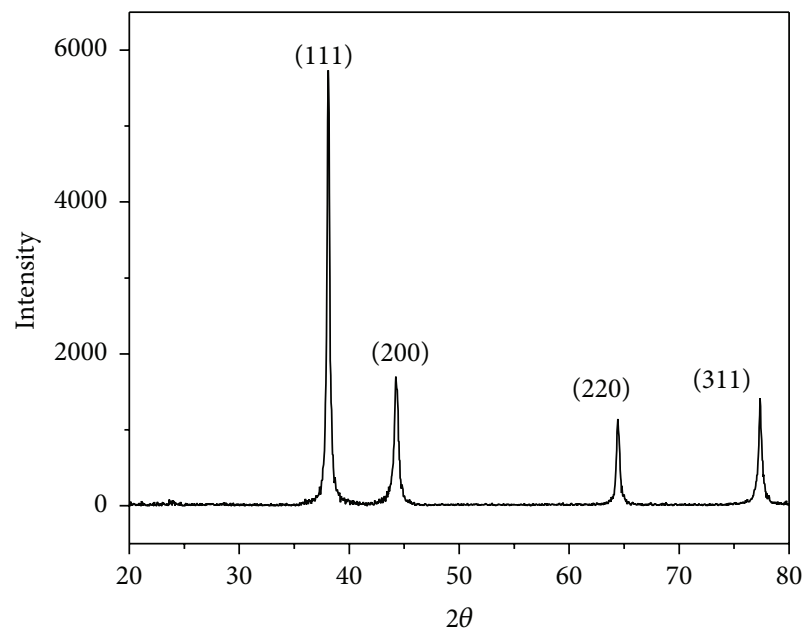

(d)

FIGURE 6: HRTEM images with fringe spacing of the GO-Ag2 composite (a), enlarge image of fringe spacing of an individual Ag nanoparticle in GO matrix (b), SAED image of the Ag NPs in GO-Ag2 nanocomposites (c), and XRD of the pure Ag NPs (d).

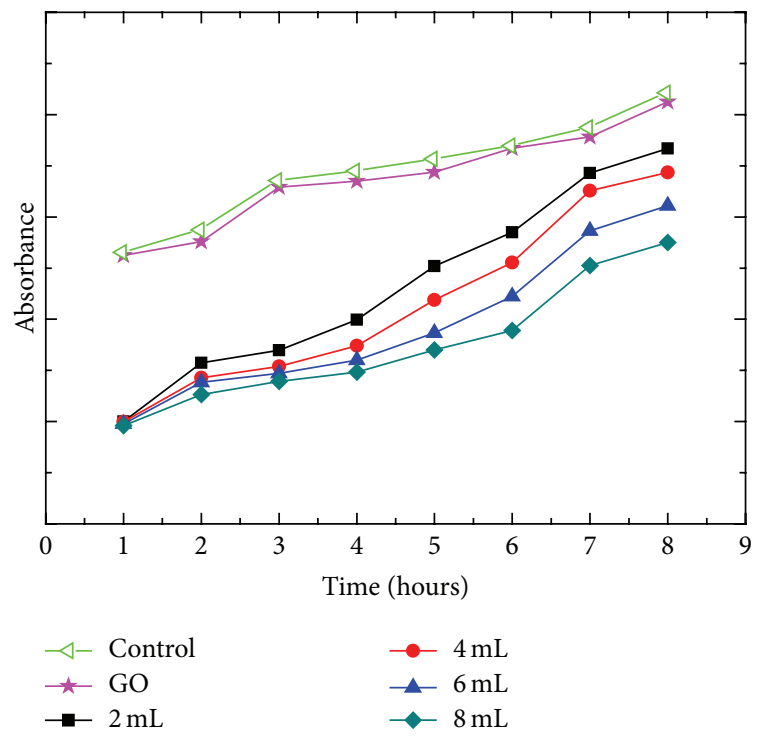

(a)

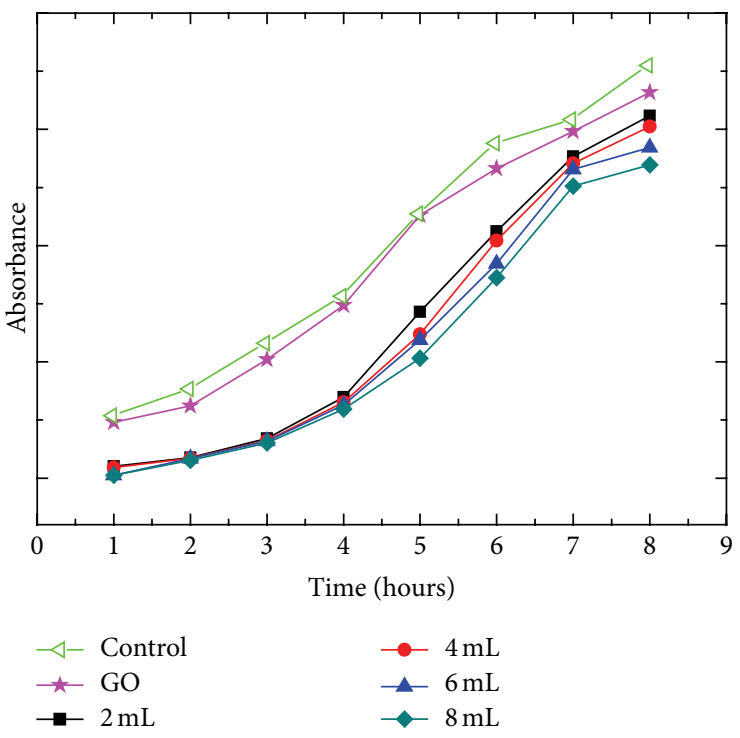

(b)

FIgURE 7: Growth kinetics curves of E. coli (a) and S. aureus (b) in LB. 


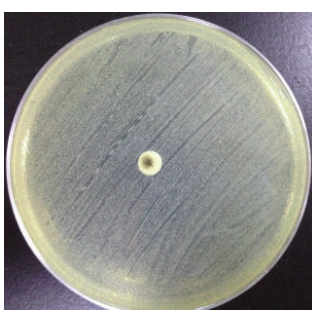

(a)

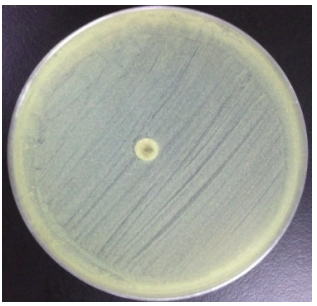

(f)

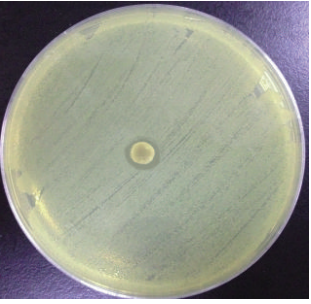

(b)

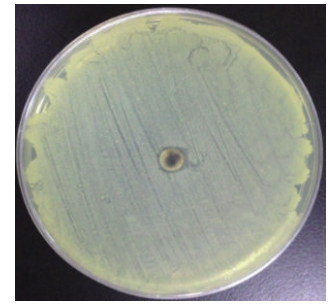

(g)

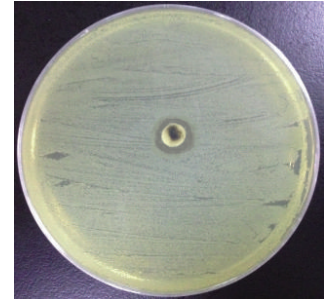

(c)

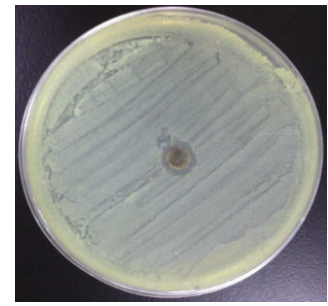

(h)

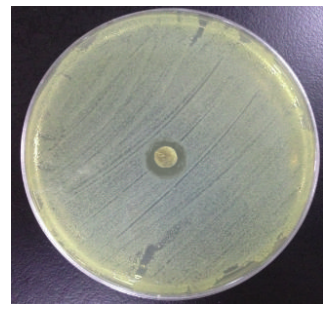

(d)

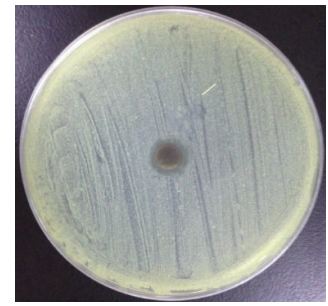

(i)

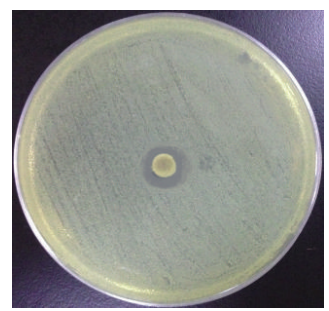

(e)

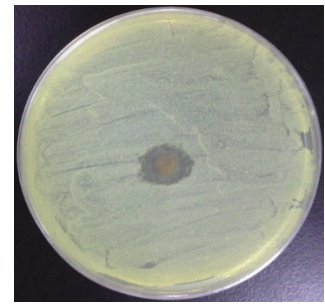

(j)

FIGURE 8: Zone of inhibition produced by different volume of Ag NPs in Ag NPs/GO nanocomposites with bacteria; zone of inhibition produced with E. coli by the paper disk of GO (control) (a), GO-Ag2 (b), GO-Ag4 (c), GO-Ag6 (d), and GO-Ag8 (e); zone of inhibition produced with $S$. aureus by the paper disk of GO (control) (f), GO-Ag2 (g), GO-Ag4 (h), GO-Ag6 (i), and GO-Ag8 (j).

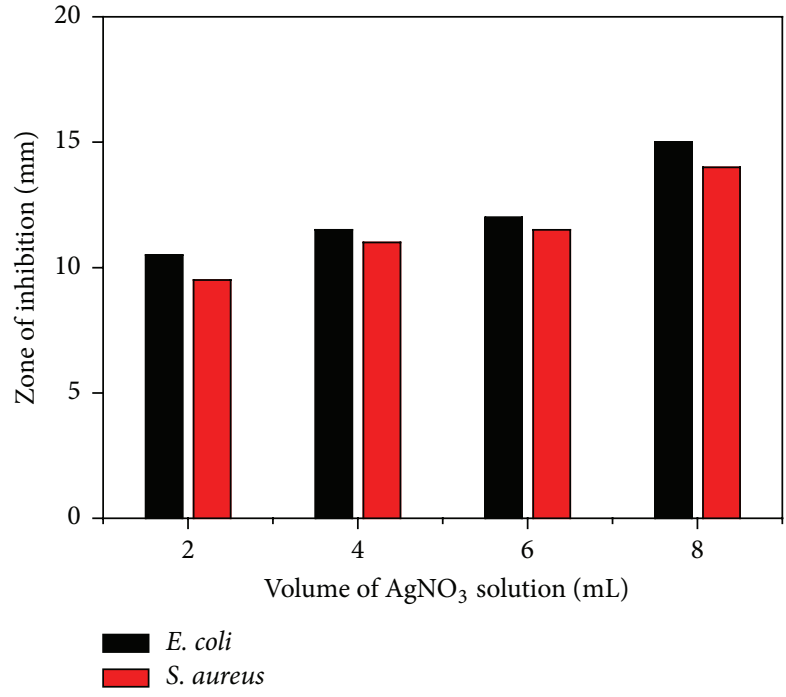

FIGURE 9: Effect of Ag NPs/GO nanocomposites on growth of E. coli and S. aureus.

thick peptidoglycan layer (thickness: about $20-80 \mathrm{~nm}$ ), which can be more resistant to $\mathrm{Ag}^{+}$diffusion [18, 47, 48]. Except loading amount, the size of Ag nanoparticles is another factor influencing their antibacterial activities. In general, the smaller Ag grains always exhibit the higher antibacterial activity [49]. However, in this work, Ag NPs/GO with the largest Ag particle size, GO-Ag8, shows the most effective antibacterial activity among all produced nanocomposites. It means that the antibacterial activities of $\mathrm{Ag}$ NPs/GO with different loading of $\mathrm{Ag}$ nanoparticles result from the combined action of concentration effect and size effect of Ag in the composites, whereas the improvement of antibacterial activities caused by increasing Ag loading is far greater than the degradation which came from the size growth of Ag nanoparticles. Besides, GO absolutely played an indispensable role in improving the antibacterial activity of $\mathrm{Ag}$ NPs/GO composites, which ensured the high dispersion of Ag nanoparticles and prevented their aggregation. Therefore, the antibacterial activities of our prepared Ag NPs/GO are the results of synergistic action of GO and Ag nanoparticles.

\section{Conclusions}

In this work, $\mathrm{Ag} \mathrm{NPs} / \mathrm{GO}$ composites have been prepared through a facile solution-phase synthesis method by direct reducing $\mathrm{AgNO}_{3}$ on GO matrix with $\mathrm{NaBH}_{4}$ as a reducing agent. The loading amount and particle size of Ag nanoparticles in Ag NPs/GO composites gradually increased with the volume increasing of $\mathrm{AgNO}_{3}$ solution added in the GO solution. Therefore, by varying the volume of $\mathrm{AgNO}_{3}$ aqueous solution added in the GO solution, Ag nanocomposites with different loading and different sizes are well-dispersed on the surface of GO sheets. All produced composite samples exhibit good antibacterial activities against Gram-negative (G-) bacterial strain E. coli and Gram-positive (G+) strain $S$. aureus. The improvement of antibacterial activities of the nanocomposites with high Ag loading results from the combined action of the size effect and concentration effect of Ag NPs, as well as synergistic action between GO and Ag NPs in $\mathrm{Ag}$ NPs/GO nanocomposites.

\section{Competing Interests}

The authors declare that there are no competing interests regarding the publication of this paper. 


\section{Acknowledgments}

This work was financially supported by the National Natural Science Foundation of China (21101136 and 21401015), the Key Project of Chinese Ministry of Education (212144), Natural Science Foundation Project of CQ CSTC (cstc2012jjA50037 and cstc2014jcyjA50012), the Natural Science Foundation of Yongchuan (Ycstc, 2014nc4001), and Chongqing University of Arts and Sciences (R2012CJ15, R2013CJ04, and ME2013 ME05).

\section{References}

[1] M. J. Allen, V. C. Tung, and R. B. Kaner, "Honeycomb carbon: a review of graphene," Chemical Reviews, vol. 110, no. 1, pp. 132$145,2010$.

[2] K. S. Novoselov, A. K. Geim, S. V. Morozov et al., "Two-dimensional gas of massless Dirac fermions in graphene," Nature, vol. 438, no. 7065, pp. 197-200, 2005.

[3] X. Li, X. Wang, L. Zhang, S. Lee, and H. Dai, "Chemically derived, ultrasmooth graphene nanoribbon semiconductors," Science, vol. 319, no. 5867, pp. 1229-1232, 2008.

[4] S. Stankovich, D. A. Dikin, G. H. B. Dommett et al., "Graphenebased composite materials," Nature, vol. 442, pp. 282-286, 2006.

[5] W. Xiao, Y. H. Zhang, and B. T. Liu, “Raspberrylike $\mathrm{SiO}_{2} @$ reduced graphene oxide@AgNP composite microspheres with high aqueous dispersity and excellent catalytic activity," ACS Applied Materials \& Interfaces, vol. 7, no. 11, pp. 6041-6046, 2015.

[6] W. Xiao, Y. H. Zhang, L. L. Tian, H. D. Liu, B. T. Liu, and Y. $\mathrm{Pu}$, "Facile synthesis of reduced graphene oxide/titania composite hollow microspheres based on sonication-assisted interfacial self-assembly of tiny graphene oxide sheets and the photocatalytic property," Journal of Alloys and Compounds, vol. 665, pp. 21-30, 2016.

[7] F. Schedin, A. K. Geim, S. V. Morozov et al., "Detection of individual gas molecules adsorbed on graphene," Nature Materials, vol. 6, no. 9, pp. 652-655, 2007.

[8] S. Stankovich, D. A. Dikin, R. D. Piner et al., "Synthesis of graphene-based nanosheets via chemical reduction of exfoliated graphite oxide," Carbon, vol. 45, no. 7, pp. 1558-1565, 2007.

[9] K. Haubner, J. Murawski, P. Olk et al., "The route to functional graphene oxide," ChemPhysChem, vol. 11, no. 10, pp. 2131-2139, 2010.

[10] R. Pasricha, S. Gupta, A. G. Joshi et al., "Directed nanoparticle reduction on graphene," Materials Today, vol. 15, no. 3, pp. 118125, 2012.

[11] H.-P. Cong, J.-J. He, Y. Lu, and S.-H. Yu, "Water-soluble magnetic-functionalized reduced graphene oxide sheets: in situ synthesis and magnetic resonance imaging applications," Small, vol. 6, no. 2, pp. 169-173, 2010.

[12] W.-P. Xu, L.-C. Zhang, J.-P. Li et al., "Facile synthesis of silver@ graphene oxide nanocomposites and their enhanced antibacterial properties," Journal of Materials Chemistry, vol. 21, pp. 45934597, 2011.

[13] J. L. hang, F. Zhang, H. J. Yang et al., "Graphene oxide as a matrix for enzyme immobilization," Langmuir, vol. 26, no. 9, pp. 6083$6085,2010$.

[14] C. Xu and X. Wang, "Fabrication of flexible metal-nanoparticle films using graphene oxide sheets as substrates," Small, vol. 5, no. 19, pp. 2212-2217, 2009.
[15] X. Xie, L. Ju, X. F. Feng et al., "Controlled fabrication of highquality carbon nanoscrolls from monolayer graphene," Nano Letters, vol. 9, no. 7, pp. 2565-2570, 2009.

[16] K. J. Woo, C. K. Hye, W. K. Ki, S. Shin, H. K. So, and H. P. Yong, "Antibacterial activity and mechanism of action of the silver ion in Staphylococcus aureus and Escherichia coli," Applied and Environmental Microbiology, vol. 74, no. 7, pp. 2171-2178, 2008.

[17] Q. L. Feng, J. Wu, G. Q. Chen, F. Z. Cui, T. N. Kim, and J. O. Kim, "A mechanistic study of the antibacterial effect of silver ions on Escherichia coli and Staphylococcus aureus," Journal of Biomedical Materials Research, vol. 52, no. 4, pp. 662-668, 2000.

[18] A. Kumar, P. K. Vemula, P. M. Ajayan, and G. John, "Silvernanoparticle-embedded antimicrobial paints based on vegetable oil," Nature Materials, vol. 7, no. 3, pp. 236-241, 2008.

[19] V. A. Oyanedel-Craver and J. A. Smith, "Sustainable colloidalsilver-impregnated ceramic filter for point-of-use water treatment," Environmental Science and Technology, vol. 42, no. 3, pp. 927-933, 2008.

[20] S. Pal, E. J. Yoon, Y. K. Tak, E. C. Choi, and J. M. Song, "Synthesis of highly antibacterial nanocrystalline trivalent silver polydiguanide," Journal of the American Chemical Society, vol. 131, no. 44, pp. 16147-16155, 2009.

[21] C. Marambio-Jones and E. M. V. Hoek, "A review of the antibacterial effects of silver nanomaterials and potential implications for human health and the environment," Journal of Nanoparticle Research, vol. 12, no. 5, pp. 1531-1551, 2010.

[22] J. R. Morones, J. L. Elechiguerra, A. Camacho et al., "The bactericidal effect of silver nanoparticles," Nanotechnology, vol. 16, no. 10, pp. 2346-2353, 2005.

[23] H. Kong and J. Jang, "Antibacterial properties of novel poly(methyl methacrylate) nanofiber containing silver nanoparticles," Langmuir, vol. 24, no. 5, pp. 2051-2056, 2008.

[24] M. Zainy, N. M. Huang, S. V. Kumar, H. N. Lim, C. H. Chia, and I. Harrison, "Simple and scalable preparation of reduced graphene oxide-silver nanocomposites via rapid thermal treatment," Materials Letters, vol. 89, pp. 180-183, 2012.

[25] L. Liu, J. C. Liu, Y. J. Wang, X. L. Yan, and D. D. Sun, "Facile synthesis of monodispersed silver nanoparticles on graphene oxide sheets with enhanced antibacterial activity," New Journal of Chemistry, vol. 35, no. 7, pp. 1418-1423, 2011.

[26] S. Liu, J. Tian, L. Wang, H. Li, Y. Zhang, and X. Sun, "Stable aqueous dispersion of graphene nanosheets: noncovalent functionalization by a polymeric reducing agent and their subsequent decoration with $\mathrm{Ag}$ nanoparticles for enzymeless hydrogen peroxide detection," Macromolecules, vol. 43, no. 23, pp. 10078-10083, 2010.

[27] S. Liu, J. Tian, L. Wang, and X. Sun, "A method for the production of reduced graphene oxide using benzylamine as a reducing and stabilizing agent and its subsequent decoration with $\mathrm{Ag}$ nanoparticles for enzymeless hydrogen peroxide detection," Carbon, vol. 49, no. 10, pp. 3158-3164, 2011.

[28] Q. Li, X. Qin, Y. Luo et al., "One-pot synthesis of Ag nanoparticles/reduced graphene oxide nanocomposites and their application for nonenzymatic $\mathrm{H}_{2} \mathrm{O}_{2}$ detection," Electrochimica Acta, vol. 83, pp. 283-287, 2012.

[29] T. Wu, S. Liu, Y. Luo, W. Lu, L. Wang, and X. Sun, "Surface plasmon resonance-induced visible light photocatalytic reduction of graphene oxide: using Ag nanoparticles as a plasmonic photocatalyst," Nanoscale, vol. 3, no. 5, pp. 2142-2144, 2011.

[30] J. Shen, M. Shi, N. Li et al., "Facile synthesis and application of Ag-chemically converted graphene nanocomposite," Nano Research, vol. 3, no. 5, pp. 339-349, 2010. 
[31] M. R. Das, R. K. Sarma, R. Saikia, V. S. Kale, M. V. Shelke, and P. Sengupta, "Synthesis of silver nanoparticles in an aqueous suspension of graphene oxide sheets and its antimicrobial activity," Colloids and Surfaces B: Biointerfaces, vol. 83, no. 1, pp. 1622, 2011

[32] J. Ma, J. Zhang, Z. Xiong, Y. Yong, and X. S. Zhao, "Preparation, characterization and antibacterial properties of silver-modified graphene oxide," Journal of Materials Chemistry, vol. 21, no. 10, pp. 3350-3352, 2011.

[33] W. S. Hummers Jr. and R. E. Offeman, "Preparation of graphitic oxide," Journal of the American Chemical Society, vol. 80, no. 6, p. 1339, 1958.

[34] L. Huang, Y. H. Zhang, H. Liu, B. T. Liu, and M. J. Tu, "Synthesis and properties of magnetic fluorescent bi-functional graphene oxide-based nanocomposites," New Journal of Chemistry, vol. 38, no. 12, pp. 5817-5824, 2014.

[35] U. Schillinger and F. K. Lücke, "Antibacterial activity of Lactobacillus sake isolated from meat," Applied and Environmental Microbiology, vol. 55, no. 8, pp. 1901-1906, 1989.

[36] F. Douglas, R. Yañez, J. Ros et al., "Silver, gold and the corresponding core shell nanoparticles: synthesis and characterization," Journal of Nanoparticle Research, vol. 10, supplement 1 , pp. 97-106, 2008.

[37] P. Sarkar, D. K. Bhui, H. Bar, G. P. Sahoo, S. P. De, and A. Misra, "Synthesis and photophysical study of silver nanoparticles stabilized by unsaturated dicarboxylates," Journal of Luminescence, vol. 129, no. 7, pp. 704-709, 2009.

[38] A. S. Reddy, C.-Y. Chen, S. C. Baker et al., "Synthesis of silver nanoparticles using surfactin: a biosurfactant as stabilizing agent," Materials Letters, vol. 63, no. 15, pp. 1227-1230, 2009.

[39] P. Mulvaney, "Surface plasmon spectroscopy of nanosized metal particles," Langmuir, vol. 12, no. 3, pp. 788-800, 1996.

[40] U. Kreibig and M. Voltmer, Optical Properties of Metal Clusters, vol. 25, Springer, Berlin, Germany, 1995.

[41] R. Bryaskova, D. Pencheva, G. M. Kale, U. Lad, and T. Kantardjiev, "Synthesis, characterisation and antibacterial activity of PVA/TEOS/Ag-Np hybrid thin films," Journal of Colloid and Interface Science, vol. 349, no. 1, pp. 77-85, 2010.

[42] J. F. Shen, M. Shi, N. Li et al., "Facile synthesis and application of Ag-chemically converted graphene nanocomposite," Nano Research, vol. 3, no. 5, pp. 339-349, 2010.

[43] Q. F. Wang, H. J. Yu, L. Zhong, J. Q. Liu, J. Q. Sun, and J. C. Shen, "Incorporation of silver ions into ultrathin titanium phosphate films: in situ reduction to prepare silver nanoparticles and their antibacterial activity," Chemistry of Materials, vol. 18, no. 7, pp. 1988-1994, 2006.

[44] I. Sondi and B. Salopek-Sondi, "Silver nanoparticles as antimicrobial agent: a case study on E. coli as a model for Gram-negative bacteria," Journal of Colloid and Interface Science, vol. 275, no. 1, pp. 177-182, 2004.

[45] J. Z. Ma, J. T. Zhang, Z. G. Xiong, Y. Yong, and X. S. Zhao, "Preparation, characterization and antibacterial properties of silver-modified graphene oxide," Journal of Materials Chemistry, vol. 21, no. 10, pp. 3350-3352, 2011.

[46] Q. Bao, D. Zhang, and P. Qi, "Synthesis and characterization of silver nanoparticle and graphene oxide nanosheet composites as a bactericidal agent for water disinfection," Journal of Colloid and Interface Science, vol. 360, no. 2, pp. 463-470, 2011.

[47] J. Tang, Q. Chen, L. Xu et al., "Graphene oxide-silver nanocomposite as a highly effective antibacterial agent with speciesspecific mechanisms," ACS Applied Materials \& Interfaces, vol. 5, no. 9, pp. 3867-3874, 2013.
[48] M. Banerjee, S. Sharma, A. Chattopadhyay, and S. S. Ghosh, "Enhanced antibacterial activity of bimetallic gold-silver coreshell nanoparticles at low silver concentration," Nanoscale, vol. 3, no. 12, pp. 5120-5125, 2011.

[49] S. V. Kumar, N. M. Huang, H. N. Lim, A. R. Marlinda, I. Harrison, and C. H. Chia, "One-step size-controlled synthesis of functional graphene oxide/silver nanocomposites at room temperature," Chemical Engineering Journal, vol. 219, pp. 217224, 2013. 

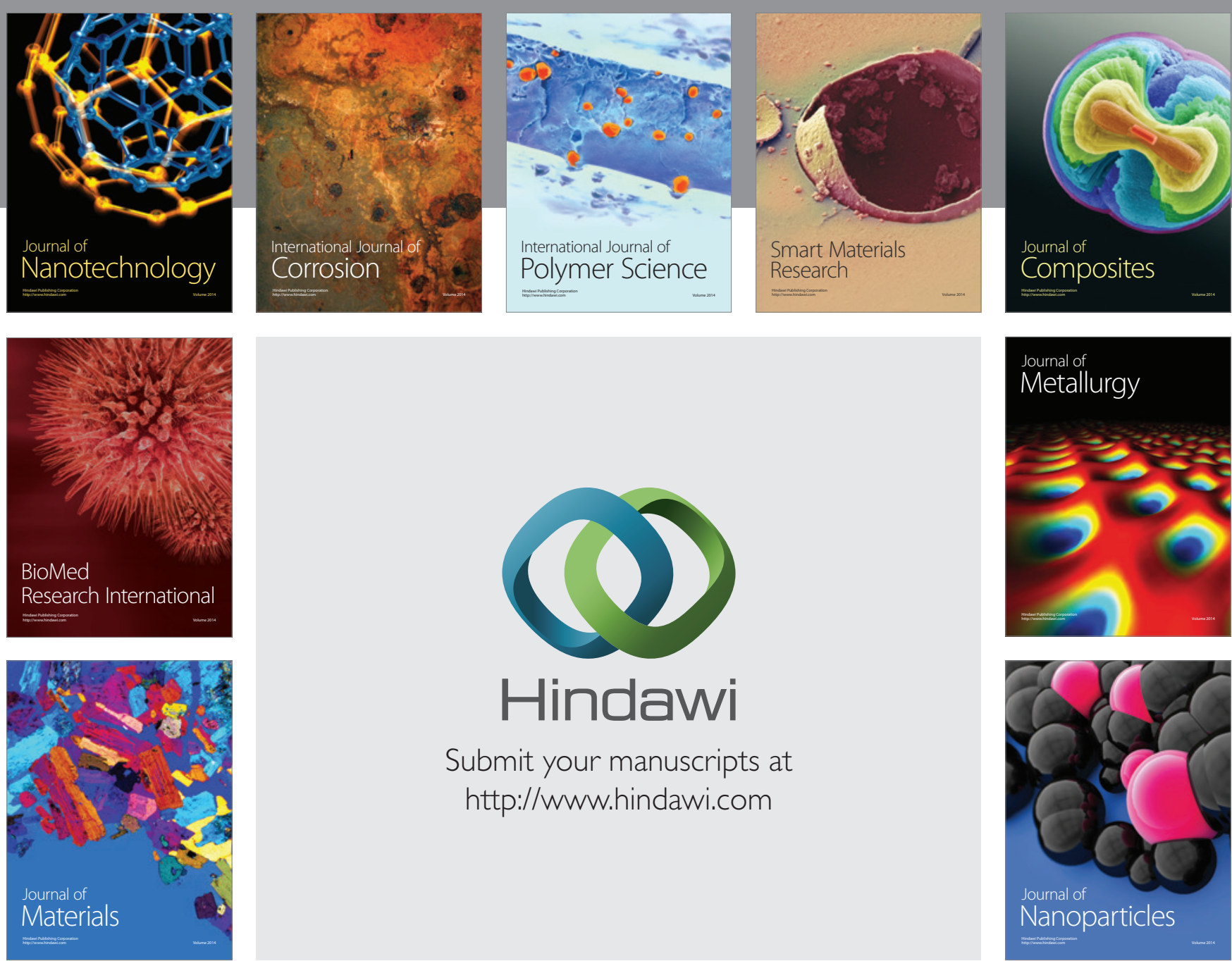

\section{Hindawi}

Submit your manuscripts at

http://www.hindawi.com

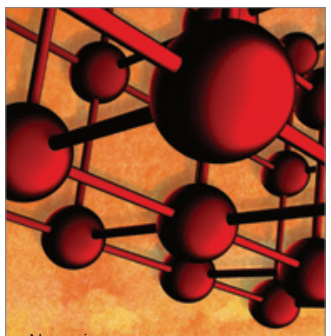

Materials Science and Engineering
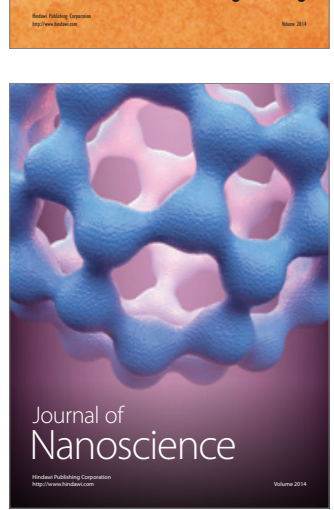
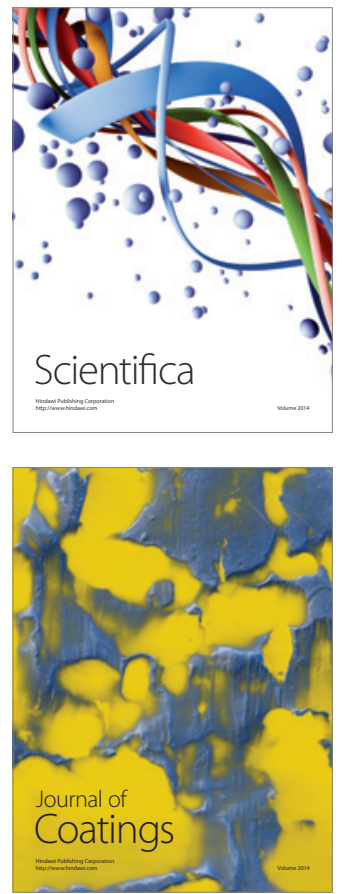
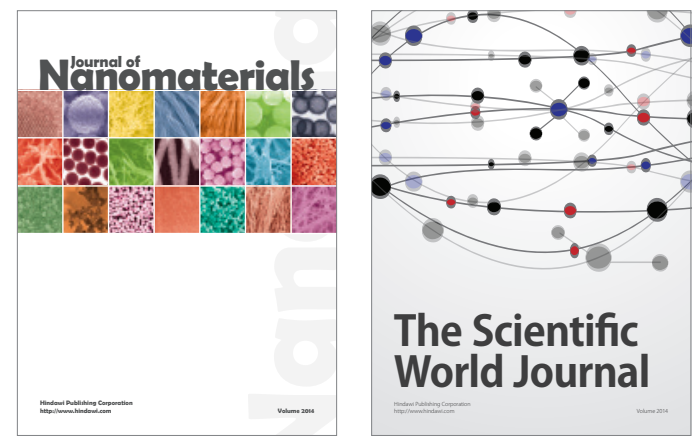

The Scientific World Journal
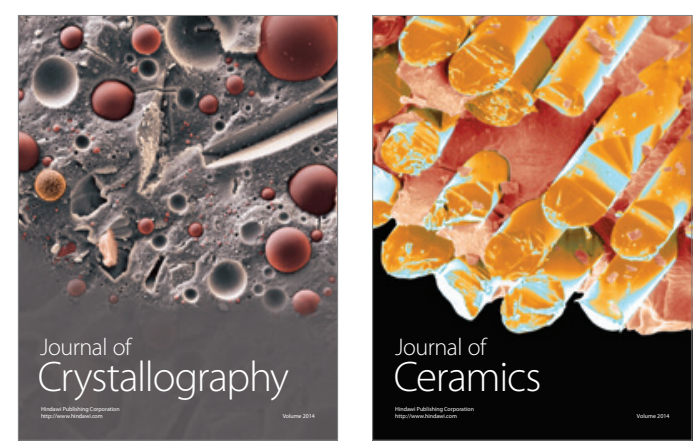
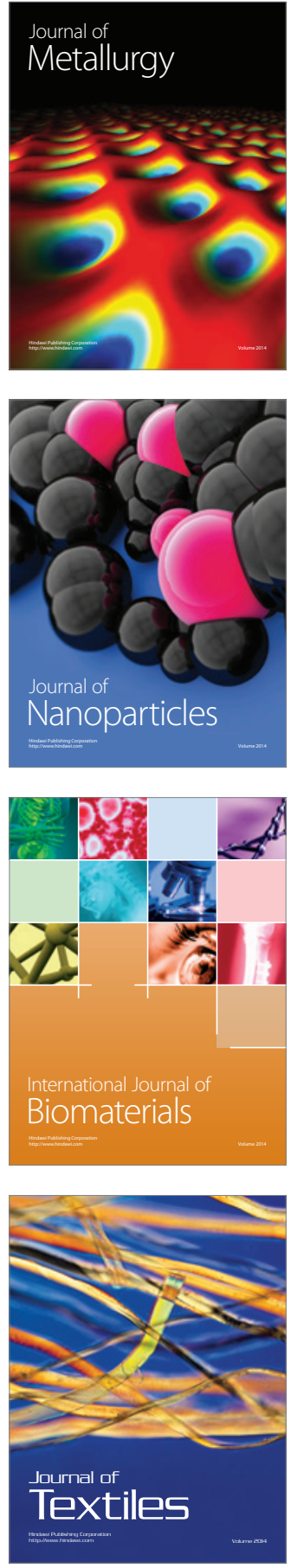